\title{
Pengaruh Kepadatan Pada Pengangkutan dengan Suhu Rendah Terhadap Kadar Glukosa dan Darah Kelulusan Hidup Ikan Nila (Oreochromis niloticus)
}

\author{
Density Influence of Transportation with Cold Water System on Blood Glucose Levels and \\ Survival Rate in Tilapia (Oreochromis niloticus) \\ Ayi Yustiati, Sofan Sidiq Pribadi, Achmad Rizal, dan Walim Lili \\ Fakultas Perikanan dan Ilmu Kelautan, Universitas Padjadjaran \\ Jl. Raya Bandung-Sumedang Km 21 Jatinangor, Sumedang UBR 40600 \\ Email :yustiati@yahoo.com
}

\begin{abstract}
Abstrak
Penelitian ini bertujuan untuk mengetahui pengaruh kepadatan pada pengangkutan dengan suhu rendah terhadap kadar glukosa darah dan kelulusan hidup ikan nila (Oreochromis niloticus). Penelitian dilaksanakan pada bulan April sampai Oktober 2016 di Laboratorium Basah dan Kolam Percobaan, Ciparanje Unpad. Metode penelitian yang digunakan yaitu metode eksperimental dengan menggunakan Rancangan Acak Lengkap (RAL) yang terdiri dari empat perlakuan dan empat ulangan. Perlakuan berupa kepadatan ikan sebanyak 5 ekor/L, 10 ekorL1, 15 ekor/L dengan pemingsanan, serta 10 ekor/L tanpa pemingsanan sebagai pelakuan kontrol. Pemingsanan dilakukan dengan cara penurunan suhu air menjadi $10 \pm 0,1{ }^{\circ} \mathrm{C}$. Pengamatan yang dilakukan terhadap kelulusan hidup setelah pengangkutan, kadar glukosa darah, kelulusan hidup setelah pemeliharaan pasca pengangkutan. Hasil penelitian menunjukkan perlakuan dengan kepadatan 15 ekor/1 menunjukan hasil terbaik, yaitu kelulusan hidup setelah pengangkutan 98,33 \%, kadar glukosa darah 192 $\mathrm{mg} / \mathrm{dL}$ serta kelulusan hidup setelah pemeliharaan pasca pengangkutan $88,33 \%$.
\end{abstract}

Kata kunci : Glukosa darah, kelulusan hidup, kepadatan, nila (Oreochromis niloticus), pengangkutan

\begin{abstract}
This research aims to find out the density influence of transportation with cold water system on survival rate and blood glucose level tilapia (Oreochromis niloticus). The research was carried out from April until October 2016 in Indoor and Outdoor Laboratory, Ciparanje Unpad. The method of research used experimental method using Completely Randomized Design (CRD), which consists of four treatments and four replications. Treatments are fish density of $5 \mathrm{fish} / \mathrm{L}, 10 \mathrm{fish} / \mathrm{L}, 15 \mathrm{fish} / \mathrm{Lwith}$ cold water system, and 10 fish/L without cold water system as control treatment. Cold water system was by decreasing the water temperature to be $10 \pm 0,1{ }^{\circ} \mathrm{C}$. Observations were the survival rate after transporting, blood glucose level, survival rate 14 days after transporting. The results showed that treatment with density of 15 fish/l showed best results, i.e. carriage of survival rate $98.33 \%$, blood glucose level $192 \mathrm{mg} / \mathrm{dL}$ and survival rate 14 days after transporting $88.33 \%$.
\end{abstract}

Keywords : Blood glucose, density, survival rate, tilapia (Oreochromis niloticus), transportation 
Ayi Yustiati : Pengaruh Kepadatan Pada Pengangkutan dengan Suhu Rendah Terhadap Kadar Glukosa dan Darah Kelulusan Hidup Ikan Nila (Oreochromis niloticus)

\section{Pendahuluan}

Kepadatan tinggi pada transportasi ikan menyebabkan aktivitas metabolisme meningkat dan konsumsi oksigen menjadi tinggi sehingga oksigen terlarut menurun kemudian menyebabkan kematian (Aini $d k k$. 2014). Peningkatan kepadatan berisiko terhadap tingkat ketahanan hidup dan kerusakan fisik yang muncul akibat gesekan antar ikan dengan wadahnya (Suwandi $d k k$. 2013). Nila memiliki sirip punggung, perut, dan sirip dubur. Sirip terseut memiliki jarijari lemah tetapi keras dan tajam seperti duri (Khairuman dan Khairul 2013). Sisik yang tajam pada nila mampu melubangi plastik kemasan saat pengangkutan. Hal tersebut sangat berbahaya serta tidak efektif dalam biaya operasional untuk plastik. Sehingga kepadatan saat pengangkutan nila hidup perlu diperhatikan. Agar nila mampu diangkut dengan kepadatan tinggi, maka perlu penanganan sebelum pengangkutan dengan menekan aktivitas metabolisme.

Metode menurunkan sistem metabolik agar ikan dalam kondisi tidak sadar dapat dilakukan dengan suhu rendah. Penggunaan suhu rendah menjadi salah satu pilihan yang aman karena tidak mengandung residu kimia juga lebih murah (Arsyad dkk. 2014). Pengangkutan sistem basah dengan menurunkan suhu media dapat menjadi pilihan untuk distribusi nila hidup dengan kepadatan yang tinggi serta menjamin kelulusan hidup yang tinggi.

Inoue dan Moraes (2006) menyatakan bahwa pengangkutan dengan mengunakan sistem tertutup dapat mengakibatkan stres dan meningkatkan plasma kortisol dan glukosa darah. Hal serupa juga diungkapkan Li et al. (2009), yang menyatakan bahwa peningkatan kadar glukosa darah merupakan efek sekunder dari stres yang diperantarai oleh pelepasan kortikosteroid dan katekolamin. Kondisi stres menyebabkan meningkatnya glukokortikoid yang berakibat pada peningkatan kadar glukosa darah untuk mengatasi kebutuhan energi yang tinggi pada saat stres. Pengangkutan dapat menyebabkan tekanan pada sistem kekebalan, menghasilkan berbagai macam penyebab meningkatnya penyakit dan kematian pada ikan (Zonneveld $d k k$. 1991). Pengukuran kadar hormon kortisol merupakan parameter stres yang akurat namun pengujiannya dibutuhkan pengetahuan dan ketelitian yang tinggi juga mahal. Maka, pengukuran kadar glukosa darah dapat digunakan sebagai parameter stres yang sederhana, efektif dan memadai untuk berbagai macam stressor (Darwisito 2006 dalam Sulmartiwi 2013). Selama ini penelitian pengangkutan nila hanya kelulusan hidup sebagai parameter uji, namun pengujian tingkat stress melalui kadar glukosa darah belum dilakukan, sehingga perlu dilakukan penelitian untuk mengetahui pengaruh kepadatan pada pengangkutan dengan suhu rendah terhadap kelulusan hidup dan kadar glukosa darah nila. Adapun tujuan penelitian ini adalah untuk mengetahui kepadatan optimal pengangkutan yang diperlukan untuk mengetahui kelulusan hidup tertinggi dan kadar glukosa darah optimal nila.

\section{Bahan dan Metode}

Bahan yang akan digunakan dalam penelitian ini, yaitu ikan nila, es batu, tabung gas oksigen. Penelitian ini dilakukan dengan metode ekperimental dengan Rancangan Acak Lengkap (RAL) terdiri empat perlakuan dan empat kali ulangan. Perlakuan yang diberikan adalah: Perlakuan A kepadatan 10 ekor/l tanpa pemingsanan suhu $10 \pm 0,1^{\circ} \mathrm{C}$, Perlakuan B kepadatan 5 ekor $/ 1$ dengan pemingsanan suhu $10 \pm 0,1{ }^{\circ} \mathrm{C}$, Perlakuan $\mathrm{C}$ kepadatan 10 ekor/l dengan penanganan suhu $10 \pm 0,1^{\circ} \mathrm{C}$, serta Perlakuan D kepadatan 15 ekor/l dengan pemingsanan $10 \pm 0,1^{\circ} \mathrm{C}$.

Parameter yang diukur meliputi kelulusan hidup setelah pengangkutan, kadar glukosa darah, kelulusan hidup setelah pemeliharaan pasca pengangkutan, suhu, $\mathrm{pH}, \mathrm{DO}$, serta ammonia.

\section{Kelulusan Hidup Ikan setelah Pengangkutan}

Kelulusan hidup atau survival rate (SR) adalah perbandingan jumlah organisme yang hidup pada akhir suatu periode dengan jumlah organisme yang hidup pada awal periode. Menurut Effendie (1997) tingkat kelulusan hidup dapat dihitung dari perbandingan jumlah ikan yang hidup pada akhir periode dengan ikan yang hidup di awal periode, dengan rumus: 


$$
\mathbf{S R}=\frac{\mathbf{N}_{1}}{\mathbf{N}_{0}} \times 100 \%
$$

Keterangan:

$\mathrm{SR}=$ survival rate atau tingkat kelulusan hidup

$\mathrm{N}_{0} \quad=$ jumlah ikan nila yang masih hidup sebelum pengangkutan (ekor)

$\mathrm{N}_{1} \quad=$ jumlah ikan nila yang masih hidup sesudah pengangkutan (ekor)

\section{Glukosa Darah}

Parameter pengamatan glukosa menggunakan metode enzimatik yang umumnya menggunakan kerja enzim yaitu salah satunya dengan cara strip test (Suryaatmadja 2003). Prinsip pemeriksaan metode ini ketika darah diteteskan pada zona reaksi tes strip. Terdapat enzim glucose dehydrogenase serta adanya coenzim (PQQ). Katalisator glukosa akan mereduksi dalam darah. Intensitas elektron yang terbentuk dalam strip setara dengan konsentrasi glukosa dalam darah. Logam emas pada strip setelah diberikan sampel darah akan bereaksi terhadap elektroda pada strip emas dan oksidase glukosa yang menghasilkan aliran listrik DC yang tidak berbahaya, sehingga alat cek mampu menginterpretasikan gula darah. Ketika arus listrik yang dihasilkan telah sebanding dengan kadar glukosa, maka alat akan menyetarakan data hasil glukosa ke dalam algoritma. Sehingga muncul angka yang menunjukan kadar gula dalam darah. Konsentrasi gula darah dapat diukur menggunakan darah utuh atau plasma. Nilai gula darah akan mengacu pada nilai plasma (Roche Diagnosticts GmbH 2008).

Kelulusan Hidup Ikan setelah Pemeliharaan Pasca Pengangkutan

$$
\mathbf{S R}=\frac{\mathbf{N}_{2}}{\mathbf{N}_{0}} \times 100 \%
$$

Keterangan:

$\mathrm{SR}=$ survival rate atau tingkat kelulusan hidup
$\mathrm{N}_{0} \quad=$ jumlah ikan nila yang masih hidup sebelum pengangkutan (ekor)

$\mathrm{N}_{2} \quad=$ jumlah ikan nila yang masih hidup setelah pemeliharaan 2 minggu pasca pengangkutan (ekor)

\section{Analisis Data}

Data kelulusan hidup setelah pengangkutan dan kadar gluksoa darah dianalisis dengan menggunaka analisis sidik ragam pada taraf kepercayaan $95 \%$. Apabila terdapat perbedaan perbedaan antar perlakuan dilanjutkan dengan uji jarak berganda Duncan pada taraf kepercayaan $95 \%$. Parameter kelulusan hidup setelah pemeliharaan pasca pengangkutan serta data kualitas air (suhu, oksigen terlarut, ammonia, dan $\mathrm{pH}$ ) dianalisis secara deskriptif.

\section{Hasil dan Pembahasan}

Kadar Glukosa Darah setelah Pengangkutan

Hormon stres berhubungan dengan kortisol, kortisol ini akan memobiliasi dan meningkatkan produksi glukosa pada ikan melalui proses glukogenesis dan glikogenolisis untuk memenuhi kebutuhan energi yang diakibatkan oleh stressor (Iwama et al. 1999 dalam Martinez et al. 2009). Kadar glukosa darah dapat dijadikan sebagai indikator stres dari ikan termasuk ikan nila (Suwandi $d k k$. 2009). Respon stres ikan nila saat pengangkutan dapat dilihat melalui salah satu parameter pengukuran darah, yaitu nilai glukosa darah. Berdasarkan hasil penelitian, perbedaan kepadatan terhadap kadar glukosa darah nila menunjukan perlakuan A 139 $\mathrm{mg} / \mathrm{dL}$, perlakuan B $125 \mathrm{mg} / \mathrm{dL}$, perlakuan C $138 \mathrm{mg} / \mathrm{dL}$, dan perlakuan D $192 \mathrm{mg} / \mathrm{dL}$ (Tabel 2).

Pengukuran kadar glukosa darah sesudah pengangkutan dibanding sebelum pengangkutan cenderung mengalami meningkatan pada setiap perlakuan. Hasil analisis sidik ragam menunjukan perbedaan kepadatan antar perlakuan yaitu $\mathrm{F}_{\text {hitung }} 3,53$ $(P>0,05)$. Selanjutnya dilakukan Uji Berganda Duncan untuk melihat perlakuan mana yang terbaik. 
Ayi Yustiati : Pengaruh Kepadatan Pada Pengangkutan dengan Suhu Rendah Terhadap Kadar Glukosa dan Darah Kelulusan Hidup Ikan Nila (Oreochromis niloticus)

Tabel 2. Kadar Glukosa Darah setelah Pengangkutan

Table 2. Blood Glucose Levels after transportation

\begin{tabular}{ccccccc}
\hline $\begin{array}{c}\text { Glukosa darah } \\
(\mathrm{mg} / \mathrm{dL}) \text { awal }\end{array}$ & Perlakuan & \multicolumn{3}{c}{ Ulangan(mg/dL) } & \multicolumn{2}{c}{$\begin{array}{c}\text { Glukosa darah akhir } \\
(\mathrm{mg} / \mathrm{dL}) \pm \text { SD }\end{array}$} \\
\hline & $\mathrm{A}$ & 116 & 147 & 162 & 131 & $139^{\mathrm{a}} \pm 19,88$ \\
\multirow{2}{*}{118} & $\mathrm{~B}$ & 146 & 72 & 140 & 140 & $125^{\mathrm{a}} \pm 35,57$ \\
& $\mathrm{C}$ & 201 & 89 & 138 & 127 & $138^{\mathrm{a}} \pm 46,51$ \\
& $\mathrm{D}$ & 173 & 232 & 187 & 179 & $192^{\mathrm{b}} \pm 26,79$ \\
\hline
\end{tabular}

Keterangan: Nilai yang diikuti huruf yang sama tidak berbeda nyata menurut uji jarak berganda Duncan pada taraf kepercayaan $95 \%$

Kadar glukosa darah awal lebih tinggi dibanding dengan hasil penelitian Suwandi dkk. 2013 dimana kadar glukosa darah nila (bobot 200-250 gram) sebesar 70-106 mg/dL sedangkan kadar glukosa awal pada penelitian ini sebesar $118 \mathrm{mg} / \mathrm{dL}$. Terdapat beberapa faktor yang mempengaruhi hasil glukosa antara lain pemuasaan dan fase umur, hal tersebut dapat mempengaruhi kandungan glikogen pada hati (Nakano dan Tomlinson 1967, Barton et al. 1988, McLeay 1977, Wedemeyer et al. 1990 dalam Martinez et al. 2009).

Kadar glukosa tertinggi terdapat pada perlakuan D yaitu $192 \mathrm{mg} / \mathrm{dL}$ (Gambar 2). Penurunan laju metabolisme dengan cara pemingsanan agar ikan pasif belum bekerja maksimal pada perlakuan D sehingga kondisi kadar gluksoa darah tetap tinggi dibanding kondisi kadar glukosa darah awal. Kepadatan 15 ekor/1 pada ikan uji saat pengangkutan menyebabkan kondisi stressor. Stressor akan diterima oleh organ reseptor kemudian informasi tersebut disampaikan ke otak bagian hipotalamus melalui sistem saraf. Selanjutnya, sel kromaffin menerima perintah melalui serabut saraf simpatik untuk mensekresikan hormon katekolamin. Hormon ini akan mengaktivasi enzim-enzim yang terlibat dalam katabolisme simpanan glikogen hati dan otot serta menekan sekresi hormon insulin, sehingga performa kadar glukosa darah mengalami peningkatan (Hastuti dkk. 2003 dalam Sulmartiwi 2013). Kadar glukosa darah yang tinggi pada perlakuan D belum mencapai level yang menyebabkan kematian nila.

Kadar glukosa terendah terdapat pada perlakuan B sebesar $125 \mathrm{mg} / \mathrm{dL}$ (Gambar 2). Kadar glukosa ini meningkat jika dibanding kadar glukosa darah pada pemeliharaan awal. Hal tersebut diduga terjadi cold-shock stress saat penanganan suhu rendah sebelum pengangkutan. Cold-shock stress terjadi ketika ikan diaklimatisasi dengan suhu air atau kisaran suhu kemudian terkena penurunan suhu yang cepat, hal tersebut dapat mengakibatkan perubahan fisiologis serta perilaku ikan. Peningkatan kadar glukosa darah diidentifikasi sebagai salah satu efek primer dari kondisi stres pada ikan. Coldshock stress akan respon neuroendokrin pada sistem saraf pusat. Selanjutnya akan terjadi respon primer dimana pelepasan hormon kortikosteroid dan katekolamin (Donaldson et al. 2008). Hormon ini akan mengaktivasi enzim-enzim yang terlibat dalam katabolisme simpanan glikogen hati dan otot serta menekan sekresi hormon insulin, sehingga glukosa darah mengalami peningkatan (Hastuti dkk. 2003 dalam Sulmartiwi 2013). 


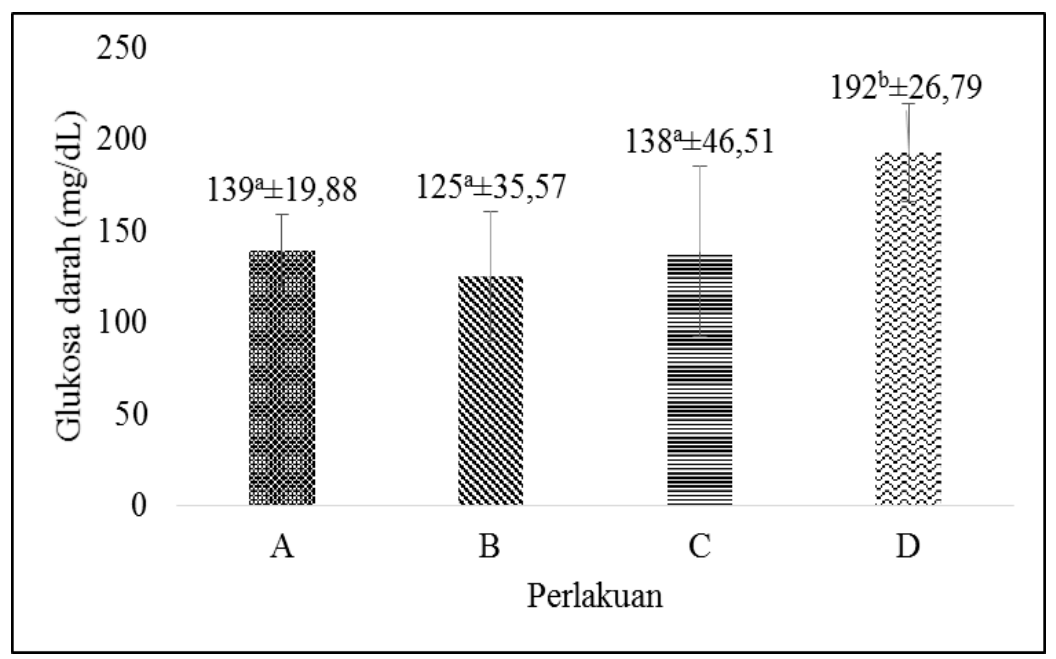

Gambar 1. Grafik Kadar Glukosa Darah

Figure 1. Blood Glucose Levels graphic

Pada saat yang bersamaan, hipotalamus otak mensekresi CRF (corticoid releasing factor) yang meregulasi kelenjar pituitari untuk mensekresi ACTH (Adenocorticotropik hormone), MSH (Melanophore-Stimulating hormone) dan $\beta$ End ( $\beta$-endorphin). Hormon tersebut akan meregulasi sekresi hormon kortisol dari sel interrenal. Kortisol akan menggertak enzimenzim yang terlibat dalam glukoneogenesis yang menghasilkan peningkatan glukosa darah yang bersumber dari non karbohidrat (Hastuti $d k k .2003$ dalam Sulmartiwi 2013)

Perlakuan A, B, dan C memiliki pengaruh yang sama terhadap kenaikan kadar glukosa darah berdasarkan uji Berganda Duncan yang ditandai dengan notasi huruf yang sama.
Pemingsanan dengan suhu rendah pada perlakuan $B$ serta $C$ belum mampu mencegah kondisi fisiologis ikan dari keadaan stres. Hal tersebut disebabkan pengaruhnya masih sama terhadap perlakuan A yang tanpa pemingsanan. Diduga ikan sudah tersadar dalam proses pengangkutan sehingga laju metabolisme ikan kembali normal.

\section{Kelulusan Hidup setelah Pengangkutan}

Berdasarkan hasil pengamatan perbedaan kepadatan terhadap kelulusan hidup nila menunjukan perlakuan A 92,50 \%, perlakuan B $100 \%$, perlakuan C 97,50\%, dan perlakuan D 98,33 \% (Tabel 1).

Tabel 1. Kelulusan Hidup setelah Pengangkutan

Table 1. Survival rate after Transportation

\begin{tabular}{|c|c|c|c|c|c|}
\hline \multirow{2}{*}{ Perlakuan } & \multicolumn{4}{|c|}{ Ulangan(\%) } & \multirow{2}{*}{$\mathrm{SR}(\%) \pm \mathrm{SD}$} \\
\hline & 1 & 2 & 3 & 4 & \\
\hline $\mathrm{A}$ & 90 & 100 & 100 & 80 & $92,50^{\mathrm{tn}} \pm 0,10$ \\
\hline B & 100 & 100 & 100 & 100 & $100^{\mathrm{tn}} \pm 0,00$ \\
\hline $\mathrm{C}$ & 90 & 100 & 100 & 100 & $97,50^{\operatorname{tn}} \pm 0,05$ \\
\hline $\mathrm{D}$ & 100 & 93 & 100 & 100 & $98,33^{\mathrm{tn}} \pm 0,03$ \\
\hline
\end{tabular}

tn = tidak berbeda nyata

Berdasarkan analisis sidik ragam, pengaruh perbedaan kepadatan terhadap kelulusan hidup nila menunjukan hasil

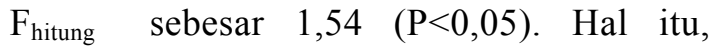
menunjukan bahwa pengaruh perbedaan kepadatan antar perlakuan tidak berbeda nyata terhadap perlakuan A sebagai kontrol. Hal tersebut menunjukan bahwa perlakuan D merupakan perlakuan terbaik, karena kepadatan tinggi pada perlakuan D memiliki pengaruh yang sama terhadap kelulusan hidup pada perlakuan A, B, dan C 
Ayi Yustiati : Pengaruh Kepadatan Pada Pengangkutan dengan Suhu Rendah Terhadap Kadar Glukosa dan Darah Kelulusan Hidup Ikan Nila (Oreochromis niloticus)

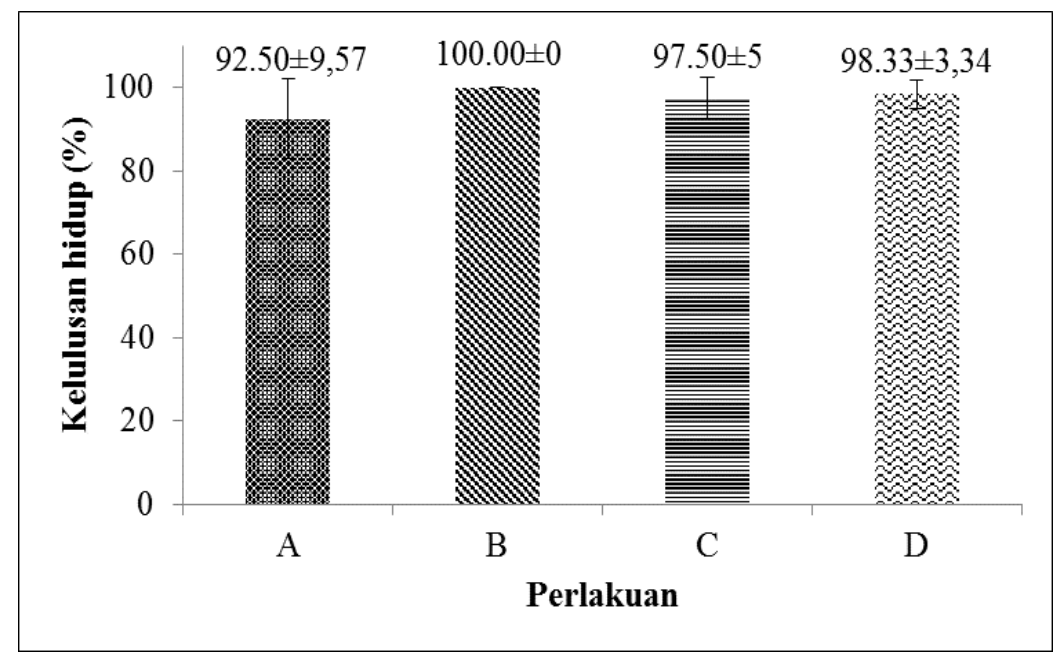

Gambar 2. Grafik Kelulusan Hidup

Figure 2. Survival rate graphic

Nila pada perlakuan $\mathrm{D}$ dipingsankan dengan cara memasukan ikan pada media air bersuhu $10 \pm 0,1{ }^{\circ} \mathrm{C}$. Setelah pingsan, nila dimasukkan ke dalam kantong plastik dengan kepadatan 15 ekor/1. Pemingsanan sebelum pengangkutan berpengaruh terhadap laju metabolisme saat proses ikan diangkut. Suhu rendah akan menekan proses metabolisme sehingga menjadi rendah. Metabolisme yang rendah akan membuat ikan pasif, maka tingkat sisa metabolisme yang dikeluarkan dari tubuh menjadi rendah. Hal tersebut serupa dengan pernyataan Syamdidi (2006) bahwa penurunan suhu menyebabkan aktivasi laju respirasi dan metabolisme ikan gurami cenderung menurun, seiring dengan penurunan suhu air media hidup ikan. Upaya peningkatan ketahanan hidup ikan dalam transportasi sistem basah dapat dilakukan dengan penurunan laju metabolisme ikan. Salah satu aktivitas fisiologis yang perlu dikaji adalah laju ekskresi. Laju ekskresi berkaitan dengan banyaknya sisa metabolisme yang dikeluarkan oleh ikan melalui feses dan urin ke dalam air yang bersifat toksik terhadap ikan (Suwandi $d k k$. 2012).

Suhu dingin akan mempengaruhi suhu badan dan suhu darah ikan, semakin dingin suhu darah tingkat viskositas darah akan mengental dan mengakibatkan aliran darah yang lebih lambat. Penurunan suhu berdampak pada penurunan konsumsi oksigen dan menurunnya produk metabolisme yang dapat bersifat racun, seperti dalam bentuk gas $\mathrm{CO}_{2}$ maupun ammonia dalam bentuk $\mathrm{NH}_{3}$ (Wedemeyer 1996 dalam Imanto 2008 dalam Wijayanti dkk. 2011). Maka, tingkat sisa metabolisme yang rendah cenderung memperlambat proses kerusakan kualitas air saat pengangkutan, sehingga ikan akan dapat bertahan hidup lebih lama saat pengangkutan.

Tingkat kelulusan hidup terendah terdapat pada perlakuan A sebesar 92,50\%. Perlakuan ini digunakan kepadatan 10 ekor/1 tanpa pemingsanan suhu $10 \pm 0,1{ }^{\circ} \mathrm{C}$. Kelulusan hidup yang rendah diduga karena kompetisi ruang yang tinggi karena kepadatan perlakuan tersebut. Ikan diangkut tanpa proses pemingsanan sehingga ikan dalam keadaan normal. Ruang yang padat pada plastik membuat ikan berkompetisi dalam mengkonsumsi oksigen terlarut untuk proses aktivitas biologis sehingga pergerakan operculum lebih aktif disertai dengan pergerakan mengambil udara. Maka menimbulkan gesekan dan benturan yang tinggi antar ikan dengan kondisi ruang yang sempit dan padat. Pergerakan operculum ikan yang aktif mengindikasikan laju metabolisme ikan sedang tinggi, sehingga proses buangan sisa metabolisme tinggi pula. Hal tesebut akan mempercepat kerusakan kualitas air saat pengangkutan. Kondisi oksigen terlarut yang rendah, luka tubuh akibat gesekan dan benturan antar ikan, serta kualitas air yang rendah diduga menjadi penyebab kematian ikan saat pengangkutan. Hal tersebut serupa 
dengan pernyataan Hepher dan Pruginin (1981) dalam Diansari (2013) peningkatan kepadatan akan diikuti dengan buangan metabolisme tubuh, konsumsi oksigen dan dapat menurunkan kualitas air. Penurunan kualitas air akan mengakibatkan ikan menjadi stres sehingga rentan mengalami kematian. Menurut Diansari (2013) kematian ikan terjadi karena adanya faktor ruang gerak ikan yang semakin sempit sehingga dapat memberikan pengaruh tekanan pada ikan yang dapat mengakibatkan daya tahan tubuh menjadi menurun. Ikan dapat mengalami stres dan bahkan dapat menimbulkan kematian.

Kelulusan Hidup setelah Pemeliharaan Pasca Pengangkutan
Pemeliharaan dilakukan selama 14 hari setelah pengangkutan. Setiap ulangan disatukan dalam masing-masing perlakuan. Berdasarkan hasil pengamtan nilai kelulusan hidup menunjukan perlakuan A $72,50 \%$, B $85,00 \%$, C 85,00 \%, dan D 88,33\% (Gambar 3). Kelulusan hidup terendah terdapat pada perlakuan A hal ini disebabkan saat proses pengangkutan tidak diberi penanganan, sehingga dengan kepadatan 1 ekor/l terjadi kompetisi ruang yang tinggi menyebabkan gesekan dan benturan terhadap ikan satu dengan yang lain. Hal sebut dapat menyebabkan kerusakan tubuh yang dapat menyebabkan infeksi yang dapat terserang hama dan penyakit ikan.

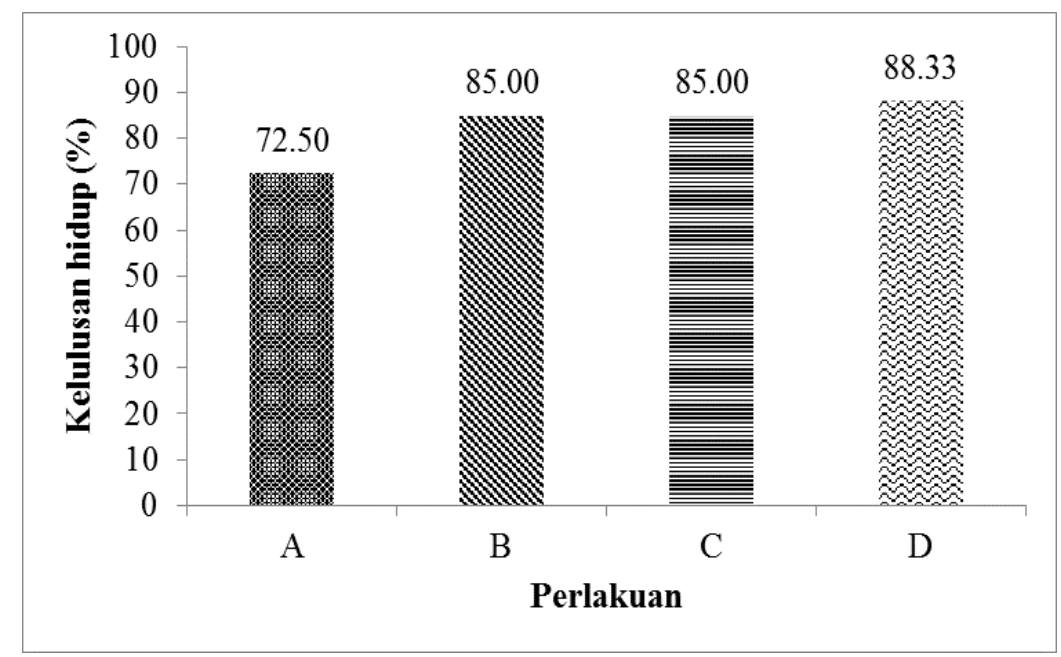

Gambar 3. Grafik Kelulusan Hidup setelah Pemeliharaan Pasca Pengangkutan

Figure 3. Graphic of Survival rate after Maintenance Post-Transport

Pemingsanan dengan suhu rendah berdampak pada proses keberlangsungan pemeliharaan, terlihat dengan kepadatan yang sama antara $\mathrm{A}$ dan $\mathrm{C}$ menunjukan nilai berbeda terhadap kelulusan hidup. Hal tersebut dikarenakan penanganan suhu rendah mampu menekan stres yang diindikasikan kadar glukosa darah pada ikan perlakuan $\mathrm{C}$ lebih rendah dibanding perlakuan A. Hal itu menunjukan bahwa tingkat stres perlakuan $\mathrm{C}$ lebih rendah dibanding A. Maka tingkat stres akan berdampak pada efek tersier yaitu kematian (Donaldson et al. 2008).

Populasi yang padat pada kolam memicu kompetisi ruang, sehingga tingkat gesekan dan benturan pada ikan semakin tinggi. Hal tersebut menyebabkan ikan pada tubuh luka dan infeksi. Infeksi yang disebabkan luka akan menyebabkan ikan stres.

Kematian pada perlakuan D lebih banyak dibanding perlakuan $\mathrm{B}$ dan $\mathrm{C}$, namun terlihat pada Gambar 3. nilai kelulusan tertinggi terdapat pada perlakuan D. Hal ini dikarenakan jumlah ikan saat awal pemeliharaan lebih banyak dibanding perlakuan $\mathrm{B}$ dan $\mathrm{C}$ yang disebabkan perlakuan kepadatan sehingga penurunan nilai kelulusan hidup karena kematian tidak besar. Kadar glukosa yang tinggi pada perlakuan D dikarenakan tingginya kepadatan saat proses pengangkutan. Namun 
Ayi Yustiati : Pengaruh Kepadatan Pada Pengangkutan dengan Suhu Rendah Terhadap Kadar Glukosa dan Darah Kelulusan Hidup Ikan Nila (Oreochromis niloticus)

karena proses pemingsanan, ikan pada perlakuan D menjadi pasif sehingga tidak banyak yang terluka akibat benturan dan gesekan. Sehingga ikan pada perlakuan D dapat bertahan hidup lebih baik dibanding ikan pada perlakuan A selama 14 hari pasca pengangkutan.

\section{Suhu}

Kondisi suhu pada awal pemeliharaan di daerah Cimalaka sekitar $23,5{ }^{\circ} \mathrm{C}$. Kondisi suhu ini masih dikategorikan layak untuk kehidupan ikan nila. Kondisi suhu setelah pengangkutan berkisar $23,1-25,9^{\circ} \mathrm{C}$.

Kondisi suhu pemeliharaan pasca pengangkutan berkisar $22,9-24,1^{\circ} \mathrm{C}$. Kondisi suhu ini masih layak untuk kehidupan ikan nila, namun belum mencapai kondisi optimum untuk pertumbuhan dan perkembangbiakan. Kisaran suhu air normal untuk hidup nila kisaran $20-32{ }^{\circ} \mathrm{C}$, namun kisaran suhu optimum untuk pertumbuhan dan perkembangbiakan adalah $25-30{ }^{\circ} \mathrm{C}$ (SNI 7550: 2009).

\section{Oksigen Terlarut atau Dissolved Oxygen (DO)}

Kondisi oksigen terlarut atau dissolved oxygen (DO) pada awal pemeliharaan di daerah Cimalaka sekitar $4 \mathrm{mg} / \mathrm{l}$. Kondisi DO ini layak untuk kehidupan ikan nila.

Kondisi DO pada pemeliharaan pasca pengangkutan yang terletak di Ciparanje sekitar $4 \mathrm{mg} / \mathrm{l}$. Kondisi ini masih dalam kategori layak untuk kehidupan ikan nila karena kondisi DO untuk kehidupan nila berkisar 3-5 mg/l (SNI 7550: 2009).

\section{Ammonia $\left(\mathrm{NH}_{3}\right)$}

Kondisi ammonia pada pemeliharaan di Cimalaka sekitar 0,009. Kondisi ini masih layak untuk kelangsungan hidup nila. Kondisi ammonia pada pemeliharaan pasca pengangkutan menunjukan 0,009-0,06. Kondisi ini masih layak untuk kehidupan nila dimana ammonia untuk kehidupan ikan nila yaitu 0,02 mg/l (SNI 7550: 2009).

\section{Derajat Keasaman atau $p H$}

Kondisi pH pada pemeliharaan di Cimalaka sebesar 7,67. Kondisi ini masih layak untuk kehidupan nila. Setalah proses pengangkutan kondisi $\mathrm{pH}$ menurun menjadi kisaran 6,136,75. Kondisi pemeliharaan pasca pengangkutan berkisar 7,23-7,55. Kondisi ini masih layak untuk kehidupan nila, karena nila mampu hidup pada kisaran $\mathrm{pH}$ air 5-11, namun titik optimum pada kisaran $\mathrm{pH}$ 7-8 (SNI 7550: 2009).

\section{Simpulan dan Saran}

\section{Simpulan}

Kepadatan ikan Nila (Oreochromis niloticus) terbaik pada pengangkutan dengan suhu rendah adalah 15 ekor per liter air, menghasilkan kadar glukosa darah tertinggi yaitu sebesar $192 \mathrm{mg} / \mathrm{dL}$ dan kelulusan hidup sebesar $88,33 \%$.

\section{Saran}

Pengangkutan nila hidup selama 3 jam dapat dilakukan menggunakan kepadatan 15 ekor/1 dengan syarat proses pemingsanan terlebih dahulu sebelum pengangkutan. Wadah pengangkutan menggunakan plastik belum mampu mengisolasi kondisi suhu sehingga perlu digunakan wadah yang mampu mengisolasi suhu dengan baik, agar penurunan tingkat stres dengan pemingsanan oleh suhu rendah dapat teramati.

\section{Daftar Pustaka}

Aini, M., M. Ali, dan B. Putri. 2014. Penerapan Teknik Imotilisasi Benih Nila (Oreochromis niloticus) Menggunakan Ekstraksi Daun Bandotan (Ageratum conyzoides) pada Transportasi Basah. Jurnal Rekayasa dan Teknologi Budidaya Perairan. (11) 2: 217-226.

Arsyad, M., W. Dhamayanthi, dan A. A. Gemaputri. 2014. Pengaruh Pemberian Suhu $8{ }^{\circ} \mathrm{C}$ terhadap Lama Waktu Pingsan Ikan Mas (Cyprinus carpio), Ikan Patin (Pangasius sp.), Ikan Lele (Clarias sp.), dan Ikan Gurame (Osphronemus gourame). Jurnal Ilmiah INOVASI. 14 (2): 110116. 
Diansari, RR. V. R., E. Arini, dan Elfitasari T. 2013. Pengaruh Kepadatan yang Berbeda terhadap Kelulushidupan dan Pertumbuhan Ikan Nila (Oreochromis niloticus) pada Sistem Resirkulasi dengan Filter Zeolit. Journal of Aquaculture Management and Technology. (2) 3: 37-45.

Donaldson, M. R., S. J. Cooke, D. A. Patterson, dan J. S. Macdonald. 2008. Review Paper: Cold Shock and Fish. Journal of Fish Biology. (73) : 14911530

Effendie, M. 1997. Biologi Perikanan. Yayasan Pustaka Nusantara. Yogyakarta.

Inoue, L. A. K. A. and G. Moraes. 2006. Stress respon of Matrinxa (Brycon cephalus) Subjected to Transportation in Plastic bag. Journal of Fisheries and Aquatic Sciences. 1 (1): 1-9.

Khairuman, H. dan K. Amri. 2013. Budidaya Ikan Nila. PT AgroMedia Pustaka. Jakarta.

Li, P., B. Ray, D. M. Gatlinn III, T. Sink, R. Chen, dan R. Lochmann. 2009. Effect of handling and transport on cortisol response and nutrient mobilization of golden shiner, Notemigonus crysoleucas. Abstrak. Journal of the World Aquaculture Society. 40 (6): 803-809.

Martinez-Porchas, M. P., L. R. MartinezCordova, dan R. Ramos-Enriquez. 2009. Cortisol and Glucose: Reliable indicators of fish stress?. PanAmerican Journal of Aquatic Sciences. 4 (2): 158-178.

Roche Diagnosticts GmbH. 2008. Accu-Che Performa Alat Monitor Gula Darah Petunjuk Penggunaan. 68298 Mannheim. Germany. www.accuchek.com. Diakses pada 27 Juli 2016 pada pukul 14.47 WIB

Standar Nasional Indonesia (SNI). 2009. SNI 7550 Produksi ikan nila (Oreochromis niloticus, Bleeker) kelas pembesaran di kolam air tenang. Badan Standardisasi Nasional ICS 65.120. Jakarta.
Sulmartiwi, L., S. Harweni, A. T. Mukti, dan Rr. J. Triastuti. 2013. Pengaruh Penggunaan Larutan Daun Bandotan (Ageratum conyzoides) terhadap Kadar Glukosa Darah Ikan Koi (Cyprinus carpio) Pasca Transportasi. Jurnal Ilmiah Perikanan dan Kelautan. 5 (1): 81-86.

Suryaatmadja, M. 2003. Pendidikan Berkesinambungan Patologi Klinik 2003. Jakarta.

Suwandi, R., R. Nugraha, dan K. E. Zulfamy. 2013. Aplikasi Ekstrak Daun Jambu Psidium guajava var. pomifera pada Proses Transportasi Ikan Nila (Oreochromis niloticus). Jurnal Pengolahan Hasil Perikanan Indonesia. 16 (1): 69-78.

Syamdidi, D. Ikasan, dan S. Wibowo. 2006. Studi Fisiologis Ikan Gurami (Osphronemus gourami) pada Suhu Rendah untuk Pengembangan Teknologi Transportasi Ikan Hidup. Jurnal Pascapanen dan Bioteknologi Kelautan dan Perikanan. 1 (1): 75-83.

Wijayanti I, E. J. Tapotabun, A. Salim, N. Nuer'aenajh, C. Litaay, R. M. S. Putri, A. O. W. Kaya, dan R. Suwandi. 2011. Pengaruh temperatur terhadap kondisi anastesi pada bawal tawar Colossoma macropomum dan lobster tawar Cherax quadricarinatus. Prosiding Pengembangan Pulau-Pulau Kecil. 7 (70): 67-76

Zonneveld, N., E. A Huisman dan J. H. Boon. 1991. Prinsip-Prinsip Budidaya Ikan. Gramedia Pustaka Utama. Jakarta. 